\title{
Singularities of the Consultation-liaison Psychiatry Care in Majadahonda Puerta de Hierro University Hospital
}

M. Magariños López ${ }^{1}$, P. Del Sol ${ }^{1}$, T. Ponte ${ }^{1}$, E. Gil ${ }^{1}$, J. Herranz ${ }^{1}$, L.M. Solari ${ }^{1}$, M.I. Hidalgo ${ }^{1}$.

${ }^{1}$ University Hospital Puerta de Hierro Majadahonda, Psiquiatría, Madrid, Spain.

\section{Objectives}

The present work consists of a descriptive analysis of the patients treated, in a year, by the Department of Consultation-liaison of Psychiatry in Majadahonda Puerta de Hierro University Hospital in Madrid.

\section{Materials and Methods:}

552 consecutive patients treated in a year by the Consultation-liason Department of Psychiatry were selected. Percentages were used for the descriptive analysis.

\section{Results and Conclusions:}

$51.8 \%$ of the sample were male and $48.2 \%$ were female. (figure 1) The first petitioner department was Pneumology (18.1\%), followed by Internal Medicine (16.8\%) (table 1)

$89.6 \%$ of the requests were for psychiatric pathology to be treated while $10.4 \%$ of the cases were considered not justified due to stable psychiatric pathology or normal emotional reactions. $85.5 \%$ of the total of the interconsultations carried out were considered opportune in time

The most prevalent psychiatric diagnosis (table 2) were affective and anxiety disorders (53\%) followed by delirium $(24.5 \%)$. While in the Pneumology department affective/anxiety disorders (54\%) and delirium (22\%) were the most common diagnosis, the contrary ocurred in the Internal Medicine department (delirium 35\%; affective/anxiety disorders 29\%). Figure 1.

Substance abuse disorders accounted for the $4.8 \%$ of the total cases (Abstinence Syndrome and Drug issues)

\begin{tabular}{|c|c|}
\hline Service & Attended \\
\hline Pneumology & $18,11 \%$ \\
\hline Internal medicine & $16,85 \%$ \\
\hline Intensive Care Unit & $5,7 \%$ \\
\hline Digestive medicine & $5,7 \%$ \\
\hline Pulmonar transplant unit & $5,6 \%$ \\
\hline General Surgery & $4,9 \%$ \\
\hline Neurosurgey & $4,2 \%$ \\
\hline Cardiology & $4,1 \%$ \\
\hline
\end{tabular}

Table 1: Consultant services

\begin{tabular}{|l|c|}
\hline Psychiatric disorder & Attended \\
\hline Axiety/affective disorders & $53 \%$ \\
\hline Delirium & $24,5 \%$ \\
\hline Related to treatment & $8,10 \%$ \\
\hline Suicide attempt & $6,20 \%$ \\
\hline Deprivation Syndrome (alcohol) & $2,80 \%$ \\
\hline Drug issues & $2 \%$ \\
\hline Eating disorders & $1,82 \%$ \\
\hline Conversion disorder & $0,80 \%$
\end{tabular}

Table 2: Most frequent diagnosis

$\%$ of diagnosis attended by specialities

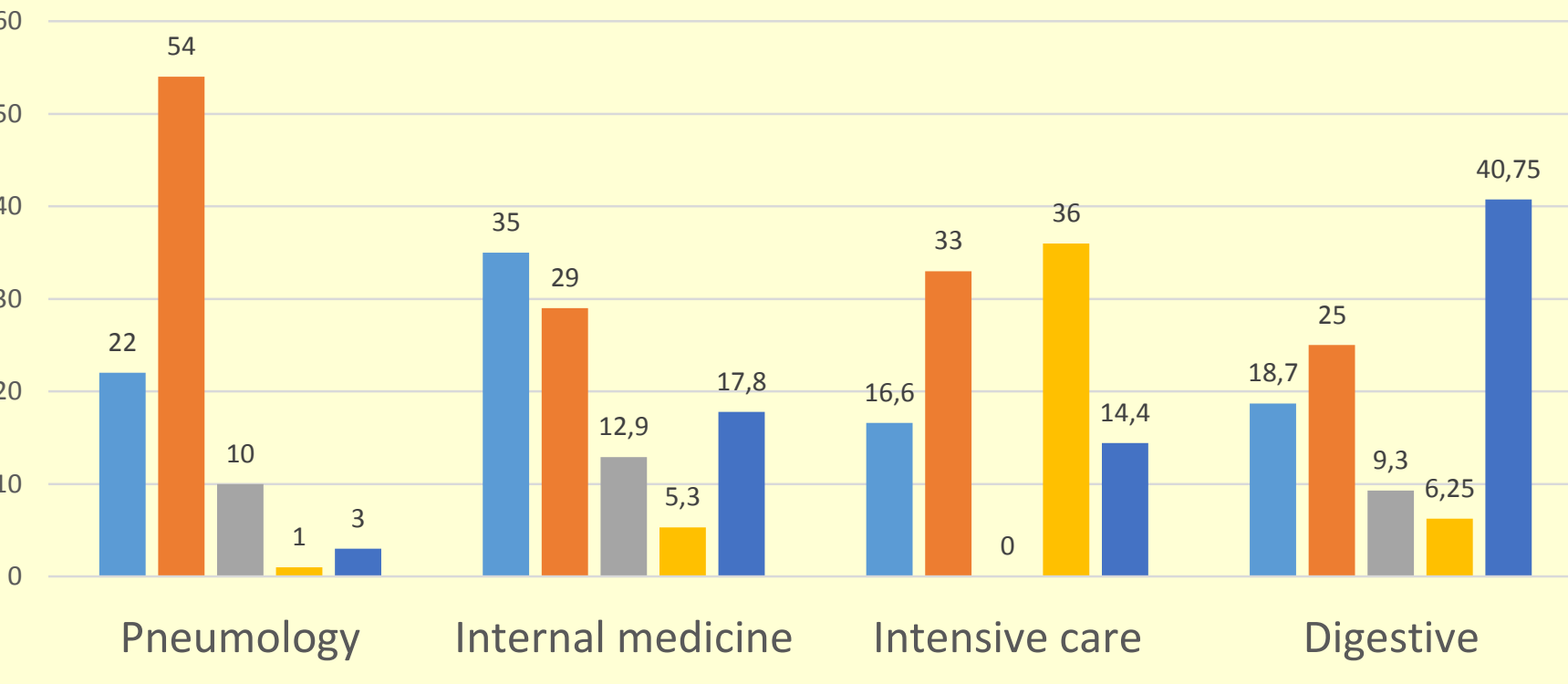

- Delirium $\square$ Anxiety/affective $\square$ Treatment $\square$ Suicide attempt $\square$ Others

Figure 1: Most frequent diagnosis by specialities

Our results are concordant with the literature on the most prevalent pathologies (delirium, anxiety disorders and depression). Unlike other studies in which substance abuse disorder appears as the third diagnosis, in our sample it only represents $4.8 \%$ of the cases. It is possible that other medical specialties do not give enough importance to substance use disorders or know how to manage this problem. More research is needed to assess these issues.

\section{References:}

- Referral patterns in a consultation liaison psychiatry service in India: A comparison with the Western world Article in Press: Corrected Proof.Rakesh Kumar Chadda, Koushik Sinha Deb, Ananya Mahapatraand Rishi Gupta. Gen Hosp Psychiatry. 2019 Jul 